\title{
Difficult Vascular Access
}

National Cancer Institute

\section{Source}

National Cancer Institute. Difficult Vascular Access. NCI Thesaurus. Code C99945.

Access to the subject's vasculature is troublesome or formidable. (ACC) 